\title{
CARACTERIZAÇÃO MORFOFISIOLÓGICA DE CLONES PRECOCES E TARDIOSDE BATATA VISANDO À ADAPTAÇÃO A CONDIÇÕES TROPICAIS $\left({ }^{1}\right)$
}

\author{
FELIPE LOPES DA SILVA $\left({ }^{2}\right)$; CÉSAR AUGUSTO BRASIL PEREIRA PINTO $\left({ }^{2 *}\right)$; JOSÉ DONIZETI ALVES $\left({ }^{2}\right)$; \\ FLÁVIO RODRIGO GANDOLFI BENITES $\left({ }^{2}\right)$; CRISTIANA MOURA ANDRADE $\left({ }^{2}\right)$; \\ GABRIEL BELFORT RODRIGUES $\left({ }^{2}\right)$; ANDRÉ LUIZ LEPRE $\left({ }^{2}\right)$; LEONARDO LOPES BHERING $\left({ }^{2}\right)$
}

\begin{abstract}
RESUMO
Os objetivos do trabalho foram avaliar os processos de crescimento, de tuberização e de partição de matéria seca em tubérculos de clones de batata precoces e tardios ao longo do ciclo vegetativo. Avaliouse, ainda, a viabilidade do uso desses caracteres morfofisiológicos para a seleção de clones mais adaptados às condições tropicais. O trabalho foi desenvolvido em Lavras (MG), na safra das águas (agosto a dezembro de 2005). Os clones tardios foram mais produtivos que os precoces, devido ao crescimento mais vigoroso, à maior longevidade da área foliar fotossinteticamente ativa, à maior taxa de tuberização e ao período mais longo para enchimento de tubérculos. Os teores de clorofila $a, b$ e total, a área foliar, a duração da área foliar, a taxa de crescimento relativo e a taxa assimilatória líquida para os tubérculos foram relevantes na diferenciação dos clones tardios e precoces. Sugere-se como estratégia possível para aumentar a produtividade da cultura da batata em regiões tropicais, a seleção de clones com ciclo vegetativo mais longo.
\end{abstract}

Palavras-chave: Solanum tuberosum, análise de crescimento, partição de matéria seca, stay-green.

\section{ABSTRACT \\ MORPHOPHYSIOLOGICAL CHARACTERIZATION OF EARLY AND LATE POTATO CLONES FOR ADAPTATION TO TROPICAL CONDITIONS}

The objective of this research was to evaluate the growth, tuberization and dry matter partitioning to tubers of early and late potato clones during the vegetative growth. Besides, it was studied the viability for using morphophysiological traits as parameters to select clones more adapted to tropical conditions. The study was conducted in Lavras, Minas Gerais State, Brazil during the rainy season (August to December of 2005). Late clones were more productive than early clones at the end of the growth cycle, due to the more vigorous growth, longer duration of the photosynthetically active leaf area, the greater tuberization speed and the prolongation of tuber bulking period. Results also suggest that the morphophisiological traits used in this study are important to evaluate clones more adapted to the tropical conditions. The following physiological traits were relevant to differentiate late and early clones and should be used in breeding programs aimed at obtaining clones more adapted to the tropical conditions: content of chlorophylls $a, b$ and total of the upper canopy, leaf area, leaf area duration, relative growth rate, and net assimilation rate to tubers. The results of this study suggest that one strategy that could be used to increase potato tuber yield in the tropics is the selection for a longer growth cycle.

Key words: Solanum tuberosum, growth analysis, dry matter partitioning, tuberization, morphophysiological index, stay-green.

$\left({ }^{1}\right)$ Recebido para publicação em 9 de abril de 2007 e aceito em 6 de janeiro de 2009.

$\left(^{2}\right)$ Departamento de Biologia, Universidade Federal de Lavras, Caixa Postal 3037, 37200-000 Lavras (MG), Brasil. E-mail: cesarbrasil@ufla.br (*) Autor correspondente; lipells@yahoo.com.br,jdalves@ufla.br, frgbenites@yahoo.com.br, cristianama@yahoo.com.br, gabelfort@yahoo.com, lepre10@yahoo.com.br, leobhering@yahoo.com.br. 


\section{INTRODUÇÃO}

As principais cultivares de batata (Solanum tuberosum L.) utilizadas no Brasil, como Ágata, Monalisa, Asterix, Atlantic, entre outras, foram melhoradas para as condições de dias longos e temperaturas amenas dos países temperados. Quando submetidas às condições tropicais, recebem a influência das altas temperaturas e do fotoperíodo mais curto que reduzem sua produtividade (KoOMAN et al., 1996a).

Embora os produtores procurem as áreas e as épocas mais adequadas ao plantio com relação a temperaturas amenas, frequentemente observam-se nessas regiões temperaturas acima das ideais, principalmente na safra que se estende de agosto a dezembro.

As altas temperaturas $\left(>25{ }^{\circ} \mathrm{C}\right)$ causam redução da produção de tubérculos devido à diminuição na capacidade fotossintética, ao aumento das perdas com a respiração e à restrição da partição de fotoassimilados para os tubérculos (REYNOLDS et al., 1990). Ocorre ainda perda da qualidade pela diminuição do teor de matéria seca e o aumento da incidência de desordens fisiológicas nos tubérculos, como embonecamento e rachaduras (MeNZEL, 1985; Menezes et al., 1999).

Em trabalho realizado em Lavras, sul de Minas Gerais, SILVA e PINTO (2005) sugerem, para aumentar a produtividade da batata em regiões tropicais, a seleção de clones de ciclos vegetativos mais longos, e que a maior produção desses clones pode ser função da sua maior eficiência fotossintética e da possível condição de stay-green. Nos clones tardios ocorre maior longevidade das folhas, com prolongamento do período de formação e de enchimento dos tubérculos proporcionando aumentos significativos na produção de tubérculos (Griffith et al., 1984; KoOMAn e RabBinGE, 1996). Outro fator capaz de interferir na produção final é a remobilização de fotoassimilados e de nitrogênio da parte aérea para os tubérculos acarretando redução da longevidade das folhas, em especial nos clones precoces (MOORBY, 1970).

Apesar de vários estudos realizados na área de fisiologia vegetal, os mecanismos de resistência e tolerância ao calor não estão totalmente elucidados (Frusciante et al., 1999). Entre os mecanismos fisiológicos relacionados com a tolerância ao calor em batata, citam-se a maior eficiência fotossintética a altas temperaturas (Wolf et al., 1990) e a menor taxa de degradação de clorofila sob estresse térmico.

Os objetivos deste trabalho foram avaliar os processos de crescimento, de tuberização e de partição de matéria seca para os tubérculos em clones de batata precoces e tardios ao longo do ciclo vegetativo, empregando caracteres morfofisiológicos, e verificar a viabilidade do uso desses caracteres para auxiliar na seleção de clones mais adaptados às condições tropicais.

\section{MATERIAL E MÉTODOS}

Foram utilizados dois clones de ciclo vegetativo precoce, CBM 16-15 e CBM 2-21, e dois de ciclo vegetativo tardio, CBM 22-19 e CBM 2-27, selecionados como tolerantes ao calor no Programa de Melhoramento da Batata da Universidade Federal de Lavras (UFLA). O experimento foi desenvolvido na safra "das águas" (agosto a dezembro/2005), em campo experimental localizado a $21^{\circ} 14^{\prime}$ de latitude sul, $40^{\circ} 17^{\prime}$ de longitude Oeste e a uma altitude de 918 m. O solo é classificado como Latossolo Roxo distrófico, de textura argilosa, originalmente sob vegetação de cerrado.

Nos sulcos de plantio foi feita a aplicação de $3.000 \mathrm{~kg} \mathrm{ha}^{-1}$ do formulado 4-14-8. Na ocasião da amontoa, aos 40 dias após o plantio, foi feita adubação de cobertura com $300 \mathrm{~kg} \mathrm{ha}^{-1}$ do formulado 20-0-20. Os demais tratos culturais foram realizados conforme as práticas normalmente recomendadas para a cultura da batata na Região Sul de Minas Gerais. A temperatura foi monitorada ao longo do ciclo vegetativo da cultura utilizando-se um termohigrógrafo (modelo FUESS). O delineamento experimental foi em blocos casualizados com três repetições e parcelas de duas plantas espaçadas de $0,30 \mathrm{~m} \times 0,80 \mathrm{~m}$. Entre as parcelas foi plantado um tubérculo da cultivar Asterix, que possui a película rosada, com a finalidade de evitar eventual mistura dos clones.

Durante o ciclo da cultura foram feitas dez amostragens, realizadas aos $30,40,50,62,70,80,88$, 106, 115 e 124 DAP. Conforme ocorria a completa senescência do clone, não eram realizadas as colheitas subsequentes. Cada uma das dez épocas de amostragem foi considerada como um experimento.

As características avaliadas em cada amostragem foram: ciclo vegetativo (DAP); produção de tubérculos em g planta ${ }^{-1}$; porcentagem de tubérculos graúdos (diâmetro $>45 \mathrm{~mm}$ ); porcentagem de matéria seca dos tubérculos; taxa de tuberização em g planta ${ }^{-1} \mathrm{dia}^{-1}$, obtida pela divisão do incremento de produção de tubérculos entre duas amostragens, pelo número de dias entre as respectivas amostragens; matéria seca total da parte aérea em $g$ planta ${ }^{-1}$; partição, em porcentagem, de matéria seca para os tubérculos, estimada a partir da relação entre a matéria seca dos tubérculos e a matéria seca total da 
planta; teores de clorofila $a, b$ e total das partes superior e inferior da planta em $\mathrm{mg} \mathrm{g}^{-1}$ de matéria fresca foliar, determinados por meio do método proposto por ARNON (1949); área foliar fotossinteticamente ativa em $\mathrm{m}^{2}$, obtida com o auxilio do programa computacional de análise de imagens QUANT (VALE et al., 2001); foram ainda estimados os índices taxa de crescimento relativo da planta em $\mathrm{g}$ $\mathrm{g}^{-1}$ de folha planta ${ }^{-1}$ dia $^{-1}$ e a duração da área foliar em $\mathrm{m}^{2}$ de folha planta ${ }^{-1} \mathrm{dia}^{-1}$, descritos por RADFORD (1967).

Foi avaliada também a taxa assimilatória líquida para os tubérculos em $\mathrm{g}$ de tubérculos $\mathrm{m}^{-2} \mathrm{de}$ folha planta ${ }^{-1} \mathrm{dia}^{-1}$. Para esse fim, utilizou-se um estimador modificado em relação ao descrito por RADFORD (1967), em que se substituiu o valor da matéria seca total da planta - parte aérea e tubérculos - pela matéria seca dos tubérculos. Assim, o novo estimador da taxa assimilatória recebeu a denominação de taxa assimilatória líquida para os tubérculos.

\section{RESULTADOS E DISCUSSÃO}

Os ciclos vegetativos observados foram de 106 DAP para os clones CBM 16-15 e CBM 2-21, de 115 DAP para o CBM 22-19 e de 124 DAP para o CBM 227. Embora o ciclo vegetativo do clone CBM 22-19 tenha sido intermediário, em outros estudos realizados nas mesmas condições o seu ciclo vegetativo médio foi de 121 DAP. Características da planta como o stay green e o desenvolvimento de tubérculos similar ao do clone de ciclo tardio, possibilitam enquadrá-lo, juntamente com o clone CBM 2-27.
$\mathrm{Na}$ tabela 1 estão representados os períodos, em porcentagem de tempo, entre as colheitas, em que ocorreram os limites de temperatura média determinados durante o trabalho. A temperatura ideal para a cultura da batata está entre 15 e $20^{\circ} \mathrm{C}$ (VAN DER ZAAG e BURTON, 1978). Observa-se que tanto no período de início da tuberização (41 a $50 \mathrm{DAP}$ ) como no período de enchimento dos tubérculos (a partir de 51 DAP) ocorreram temperaturas superiores a $25{ }^{\circ} \mathrm{C}$. Temperaturas dessa magnitude podem impedir o início da tuberização ou reduzir as taxas de desenvolvimento (Menzel, 1985; ManRique, 1992). Em grande parte do ciclo vegetativo, principalmente no decorrer do período de enchimento linear dos tubérculos (entre 51 e 80 DAP), as temperaturas foram superiores a $20^{\circ} \mathrm{C}$.

Altas temperaturas estimulam o desenvolvimento da parte aérea, reduzindo a partição de fotoassimilados para os tubérculos, aumentando a intensidade da respiração e acarretando redução na produção de tubérculos (MANRIQUE et al., 1989; MENEZES et al., 1999; 2001).

Nas figuras 1 a 3 estão representados os comportamentos médios dos clones precoces e dos tardios nas dez épocas de colheitas para as características avaliadas, bem como as equações de regressão para cada grupo. Observa-se que os clones precoces foram ligeiramente mais produtivos que os clones tardios até cerca de 80 DAP. A partir deste ponto com os clones tardios houve maior produção (Figura 1A). Silva e Pinto (2005), em condições de temperaturas mais amenas (maio a agosto de 2002), observaram que os clones tardios são mais produtivos que os precoces desde aos 58 DAP. Esses resultados evidenciam as mudanças no comportamento dos grupos de clones diante das altas temperaturas.

Tabela 1. Distribuição percentual do tempo entre as amostragens que ocorreram os limites de temperaturas 10 a 14,9 ${ }^{\circ} \mathrm{C}, 15$ a $19,9{ }^{\circ} \mathrm{C}, 20$ a $24,9{ }^{\circ} \mathrm{C}, 25$ a $29,9^{\circ} \mathrm{C}$ e 30 a $35^{\circ} \mathrm{C}$

\begin{tabular}{|c|c|c|c|c|c|c|}
\hline \multirow{2}{*}{ Período entre as colheitas } & \multicolumn{5}{|c|}{ Intervalos de temperaturas $\left({ }^{\circ} \mathrm{C}\right)$} & \multirow{2}{*}{ Tempo total } \\
\hline & 10 a 14,9 & 15 a 19,9 & 20 a 24,9 & 25 a 29,9 & 30 a 35 & \\
\hline 0 a 30 DAP & 7,7 & 44,4 & 25,9 & 19,1 & 3,0 & 100 \\
\hline 31 a 40 DAP & 5,0 & 47,5 & 26,3 & 19,6 & 1,7 & 100 \\
\hline 41 a 50 DAP & 19,6 & 42,5 & 24,6 & 10,8 & 2,5 & 100 \\
\hline 51 a 62 DAP & 0,7 & 29,9 & 30,6 & 19,4 & 19,5 & 100 \\
\hline 63 a 70 DAP & 0,0 & 43,8 & 33,3 & 19,8 & 3,1 & 100 \\
\hline 71 a 80 DAP & 0,0 & 45,8 & 35,8 & 15,0 & 3,3 & 100 \\
\hline 81 a 88 DAP & 12,5 & 54,2 & 21,9 & 11,5 & 0,0 & 100 \\
\hline 89 a 106 DAP & 0,0 & 46,3 & 34,7 & 18,1 & 0,9 & 100 \\
\hline 107 a 115 DAP & 6,5 & 43,5 & 34,3 & 15,7 & 0,0 & 100 \\
\hline 116 a 124 DAP & 0,0 & 51,9 & 31,5 & 16,7 & 0,0 & 100 \\
\hline
\end{tabular}


O início da tuberização ocorreu em torno de 40 DAP (Figura 1). No período entre o início da tuberização e o desenvolvimento inicial dos tubérculos (41 a $62 \mathrm{DAP})$, houve temperaturas acima de $20{ }^{\circ} \mathrm{C}$ (Tabela 1), o que pode ter interferido na redução do desenvolvimento inicial dos tubérculos. MANRIQUE et al. (1989) comentam que também a irradiância pode afetar o desenvolvimento dos tubérculos, mas certamente a temperatura tem papel mais importante. Altas temperaturas também foram consideradas fatores limitantes à produção de tubérculos nesse estádio de desenvolvimento da planta por VAN DAM et al. (1996) e MenEzes et al. (1999).

As máximas produtividades, para ambos os grupos de clones, foram observadas aos 91,4 e no fim do ciclo vegetativo para os clones precoces e tardios respectivamente. A produção de tubérculos dos clones tardios ao final do ciclo vegetativo, foi de aproximadamente $51 \%$ maior que a produção máxima obtida pelos clones precoces (Figura 1A). Os clones
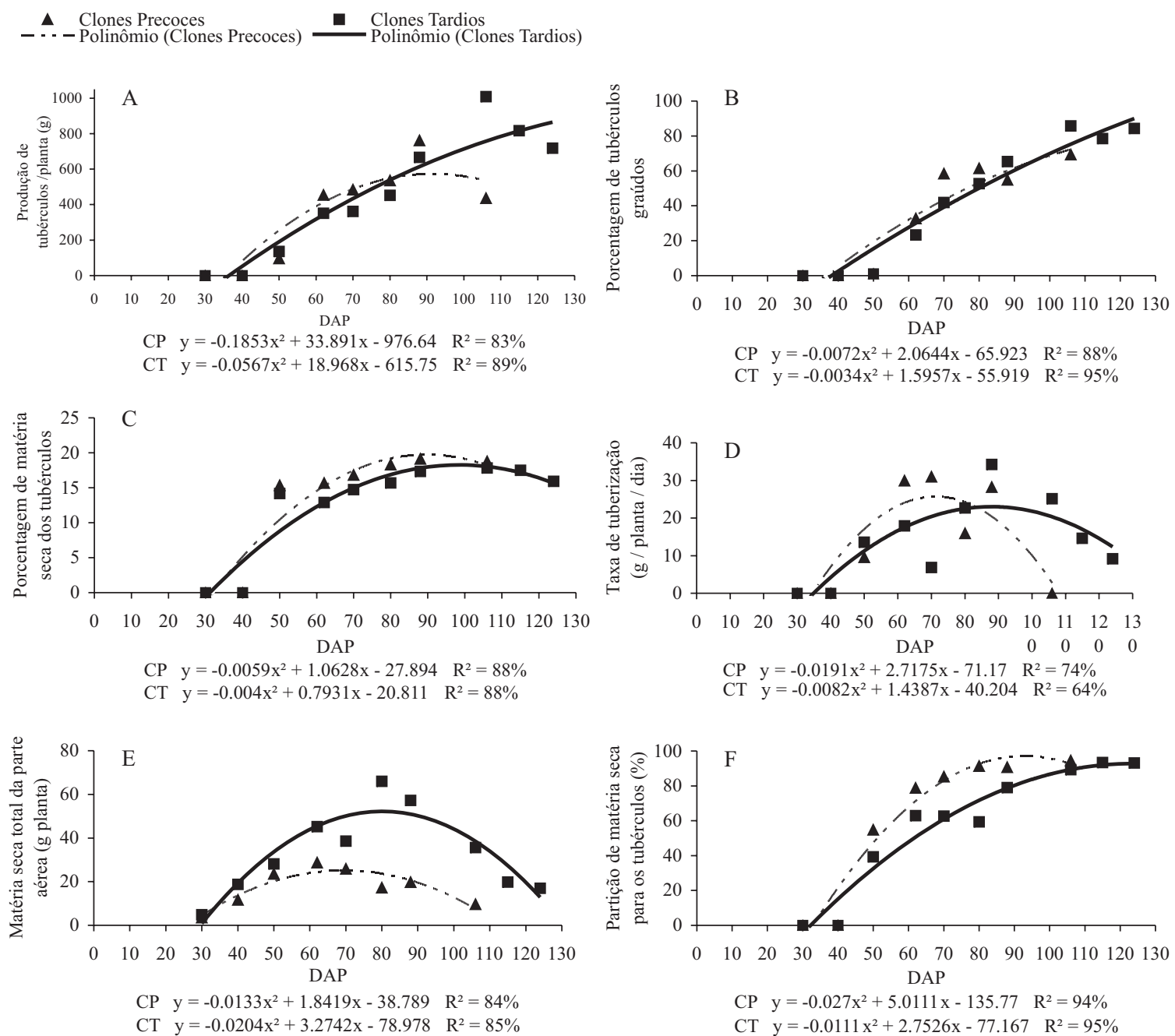

Figura 1. Produção de tubérculos (A), porcentagem de tubérculos graúdos (B), porcentagem de matéria seca dos tubérculos $(C)$, taxa de tuberização (D), matéria seca total da parte aérea (E) e partição de matéria seca para os tubérculos (F) para os grupos de clones precoces e tardios, ao longo do ciclo da batata. 
$\mathrm{Na}$ figura 1C estão representados os comportamentos dos grupos de clones para a porcentagem de matéria seca dos tubérculos. A porcentagem máxima de matéria seca dos tubérculos para os clones precoces $(19,97 \%)$ foi atingida aos 90 DAP, nos clones tardios o valor máximo (18,5\%) foi atingido aos 99 DAP. Valores de matéria seca nos tubérculos superiores a $20 \%$ são adequados para o processamento industrial da batata, e para o consumo in natura os valores obtidos são aceitáveis (Melo, 1999). Por esse experimento ter sido realizado em condições térmicas acima da ideal, contribuiu para que houvesse a queda de matéria seca dos tubérculos, conforme relatado por diversos autores (HAYNES et al., 1989; Prange et al., 1990; Menezes et al., 1999).

Nos clones precoces, houve maior tuberização até aproximadamente aos $70 \mathrm{DAP}$; a partir dessa data, os clones tardios foram os mais eficientes, obtendose a máxima taxa de tuberização aos 71 e 88 DAP, respectivamente, para os clones precoces e tardios (Figura 1D). Os clones precoces permaneceram 43 DAP no limite entre $70 \%$ e $100 \%$ do valor máximo, ou seja, entre 50 e 93 DAP; já os clones tardios permaneceram 55 dias correspondentes ao período entre 60 e 115 DAP. Esse maior período conferiu aos clones tardios incremento adicional na produção de tubérculos, possibilitando obter maior produtividade no fim do ciclo vegetativo.

Os maiores conteúdos de matéria seca na arte aérea foram atingidos aos 69 e $80 \mathrm{DAP}$ para os clones precoces e tardios respectivamente (Figura 1E). A partir desse período, houve decréscimo na matéria seca total da parte aérea, devido à senescência natural das folhas e à remobilização de nutrientes para os tubérculos (MoOrby, 1970; KoOman e Rabbinge, 1996).

Quanto à partição de matéria seca, para os clones tardios, o máximo ocorreu aos 124 DAP, com $93,5 \%$ da matéria seca total da planta acumulada nos tubérculos; para os clones precoces, o máximo de translocação de matéria seca em direção aos tubérculos ocorreu aos 93 DAP, com $97 \%$ deles acumulado nos tubérculos (Figura 1F).

KoOman et al. (1996a) mencionam que no fim do ciclo vegetativo a produção de tubérculos é determinada principalmente pela produção de matéria seca total. Assim, apesar dos clones precoces serem mais eficientes no particionamento de matéria seca para os tubérculos que os clones tardios (Figura $1 \mathrm{~F})$, os clones tardios, em função do seu desenvolvimento vegetativo mais vigoroso, são mais produtivos que os precoces. Porém, os clones precoces ficam menos tempo no campo sujeitos a fatores ambientais adversos; possibilitam sucessão de culturas mais efetivas. Todo esse processo poderá proporcionar vantagens dos clones precoces.

Com relação aos teores de clorofilas $a, b$ e total pode-se verificar que as folhas dos clones de batata precoces, anteciparam, em relação aos tardios, o processo de degradação de clorofilas na porção superior da parte aérea, característico da senescência foliar (Figura 2A, 2C e 2B). Na parte aérea inferior (2B, $2 \mathrm{D}$ e $2 \mathrm{~F}$ ), as diferenças foram menores, devido à limitação de luz, imposta pelo autossombreamento. Os teores de clorofila total foliar, frequentemente, têm sido utilizados para estimar o potencial fotossintético das plantas e as avaliações individuais das clorofilas $a$ e $b$, revelam a ligação direta com absorção e transferência de energia pelo aparato fotossintético. Enquanto a clorofila $a$ participa diretamente da etapa fotoquímica (o primeiro estágio do processo fotossintético - transferência de energia), a clorofila $b$, carotenóides e as ficobilinas que, conjuntamente, constituem os chamados pigmentos acessórios, auxilia na absorção de luz (TAIZ e Zeiger, 2009). Neste trabalho, das duas classes de clorofilas, a clorofila $a$, presente da porção superior da parte aérea, foi mais suscetível a senescência que a clorofila $b$.

Para a parte aérea superior, nos clones tardios, os teores de clorofila foram inferiores aos precoces, nos estádios iniciais de desenvolvimento das plantas e, posteriormente, tornaram-se superiores (Figuras 2A, $2 \mathrm{C}$ e $2 \mathrm{E}$ ). Dessa forma os valores dos teores de clorofilas $a, b$ e total da parte aérea superior determinaram a maior velocidade inicial da taxa de tuberização até os 50 DAP (Figura 1D) dos clones precoces em relação aos clones tardios.

Utilizando as épocas em que os teores de clorofilas $a, b$ e total atingiram valores máximos na parte aérea superior, é possível identificar o início de senescência fisiológica da planta, fazendo com que seja caracterizado o stay-green em especial nos clones tardios. O início da senescência fisiológica ocorreu, em média, aos 35 e $64 \mathrm{DAP}$, para os clones precoces e tardios respectivamente, ficando evidenciada a tendência dos clones tardios serem caracterizados pelo tipo A de stay-green (ThOMAs e HowArTH, 2000).

Quanto à área foliar total, fotossintéticamente ativa, os clones tardios tiveram valores superiores aos dos clones precoces ao longo do ciclo vegetativo (Figura 3A). A época de máxima área foliar para os clones precoces ocorreu aos 69 DAP e nos clones tardios aos 85 DAP, evidenciando o tipo A de stay green para os clones tardios. Dessa forma, os clones tardios mantêm por mais tempo as folhas fotossinteticamente ativas (Figura 3B), o que contribui para que haja maior produção final de tubérculos. 

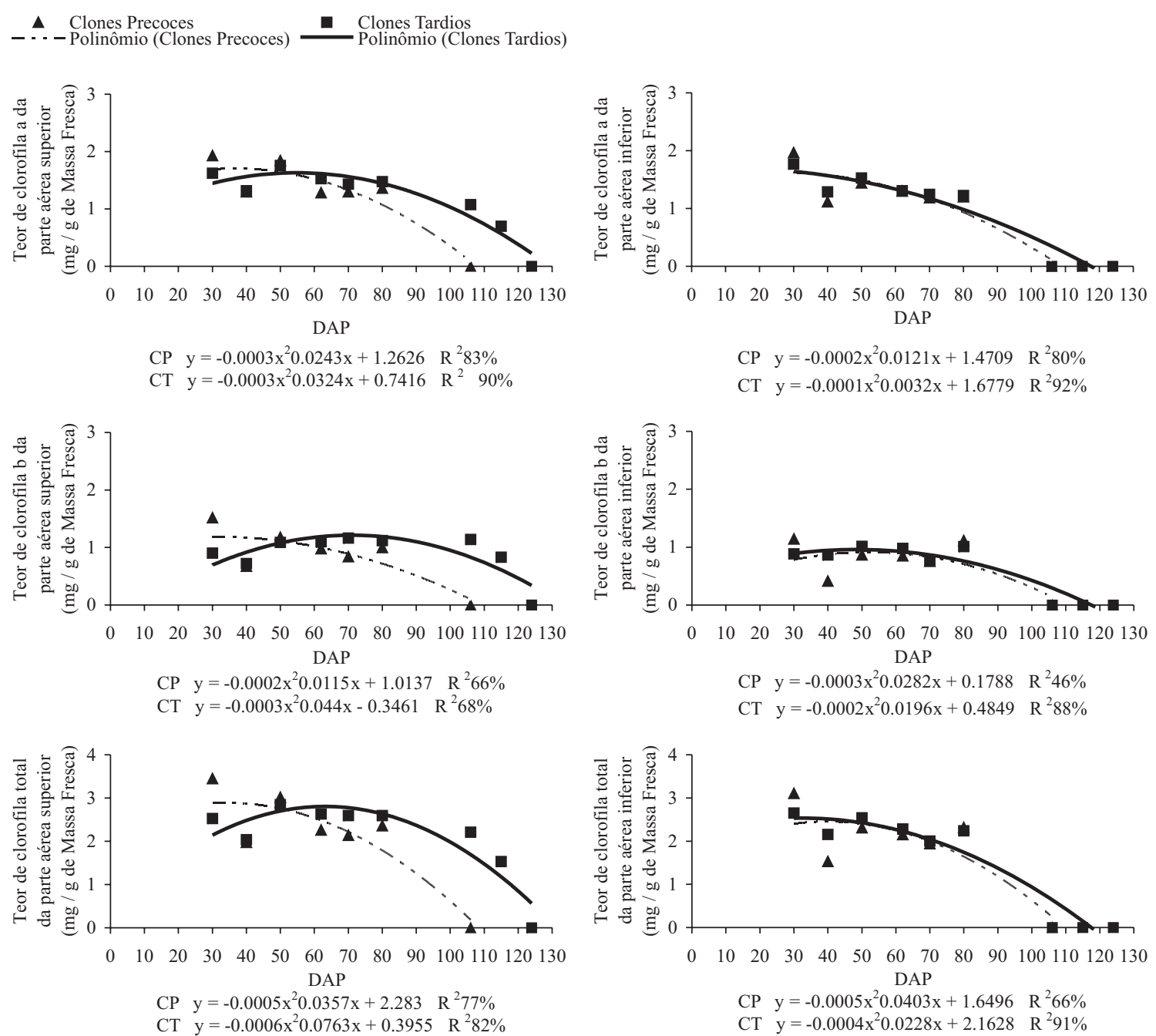

Figura 2. Teor de clorofila $a$ da parte aérea superior (A), teor de clorofila $a$ da parte aérea inferior (B), teor de clorofila $b$ da parte aérea superior (C), teor de clorofila $b$ da parte aérea inferior (D), teor de clorofila total da parte aérea superior (E) e teor de clorofila total da parte aérea inferior (F) para os grupos de clones precoces e tardios, ao longo do ciclo da batata.

Com relação à taxa de crescimento relativo, na qual se avalia o quanto de matéria seca é produzida pela planta em relação à matéria seca já existente (RADFORD, 1967), os clones precoces foram superiores aos tardios até aproximadamente aos $88 \mathrm{DAP}$; a partir desse ponto a relação foi invertida (Figura 3C).

Esse índice e a produção de tubérculos a partir do terço final do ciclo vegetativo estão diretamente relacionados, pelo fato de o incremento na matéria seca total da planta interferir na produção de tubérculos.

Quanto ao comportamento dos clones precoces e dos tardios, em relação à taxa assimilatória líquida (Figura 3D), a qual reflete o quanto de matéria seca de tubérculos é produzida por unidade de área foliar por dia, observa-se que os clones tardios foram inferiores aos precoces.
O máximo de assimilação líquida para os tubérculos ocorreu aos 82 e 81 DAP para os clones precoces e tardios respectivamente.

\section{CONCLUSÕES}

1. Os clones tardios são mais produtivos que os precoces, com crescimento mais vigoroso, maior duração da área foliar fotossinteticamente ativa, com maior taxa de tuberização e maior período de enchimento dos tubérculos.

2. Os clones tardios têm a característica staygreen do tipo A.

3. Os teores de clorofila $a, b$ e total da parte aérea superior, a área foliar, a duração da área foliar, a taxa de crescimento relativo e a taxa assimilatória líquida para os tubérculos possibilitaram a diferenciação dos clones tardios e precoces. 

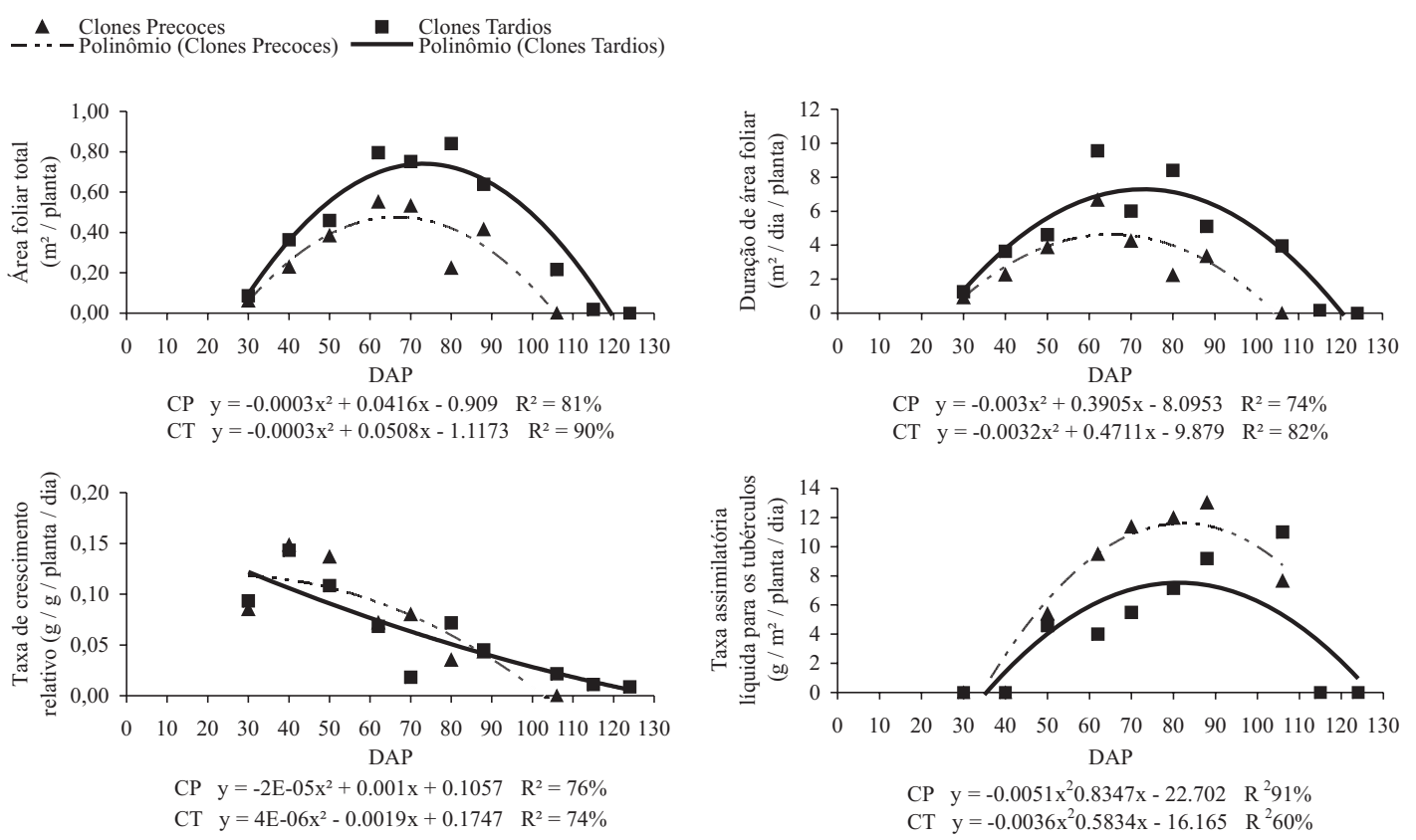

Figura 3. Área foliar total (A), duração de área foliar (B), taxa de crescimento relativo (C) e taxa assimilatória líquida para os tubérculos (D) para os grupos de clones precoces e tardios, ao longo do ciclo da batata.

\section{AGRADECIMENTOS}

Ao $\mathrm{CNPq}$ pela bolsa de pós-graduação do primeiro autor, bolsa de produtividade ao orientador e apoio parcial de recursos financeiros.

\section{REFERÊNCIAS}

ARNON D.I. Copper enzimes in isolated chloroplasts: polyphenoloxydase in Beta vulgaris. Plant Physiology, Maryland, v. 24, n.1, p.1-15, 1949.

EWING, E. E. Heat stress and the tuberization stimulus. American Potato Journal, Orono, v. 58, p.31-49, 1981.

FRUSCIANTE, L.; BARONE, A.; CARPUTO, D.; RANALLI, P. Breeding and physiological aspects of potato cultivation in the Mediterranean region. Potato Research, Wageningen, v. 42, p.265-277, 1999, Suplement.

GRIFFITH, R. L.; ALLEN, E. J.; O'BRIEN, SUSAN A.; O'BRIEN, P. J. Comparisons of growth and early yields of potato varieties of contrasting maturity classification at three sites. Journal of Agricultural Science, Cambridge, v. 103, n.2, p.443-458, 1984.

HAYNES, K. G.; WEBB, R. E.; GOTH, R. W.; WILSON, D. R. The correlation of yield and specific gravity in the USA potato breeding program. American Potato Journal, Orono, v. 66, n.9, p.587-592, 1989.

KOOMAN, P. L.; RABBINGE, R. An analysis of the relation between dry matter allocation to the tuber and earliness of a potato crop. Annals of Botany, London, v. 77, n.3, p.235$242,1996$.
KOOMAN, P. L.; FAHEN, M.; TEGERA, P.; HAVEKORT, A. J. Effects of climate on different potato genotypes. 1. Radiation interception, total and tuber dry matter production. European Journal of Agronomy, v. 5, p.193-205, 1996a.

KOOMAN, P. L.; FAHEN, M.; TEGERA, P.; HAVEKORT, A. J. Effects of climate on different potato genotypes. 2. Dry matter allocation and duration of the growth cycle. European Journal of Agronomy, v. 5, p.207-217, 1996b.

MANRIQUE, L.A. Feasibility of potato production in Hawaii. Honolulu: College of Tropical Agriculture and Human Resources, University of Hawaii, 1984. (Research series 026)

MANRIQUE, L.A. Potato production in the tropics: Crop requirements.Journal of Plant Nutrition, New York, v. 15, n. 12, p.2679-2726, 1992.

MANRIQUE, L. A.; BARTHOLOMEW, D. P.; EWING, E. E. Growth and yield performance of several potato clones grown at three elevations in Hawaii: I. Plant morphology. Crop Science, Madison, v. 29, n.2, p.363370, 1989.

MELO, P. E. Cultivares de batata potencialmente úteis para processamento na forma de fritura no Brasil e manejo para obtenção de tubérculos adequados. Informe Agropecuário, Belo Horizonte, v. 20, n.197, p.112-119, 1999.

MENEZES, C. B. de; PINTO, C. A. B. P.; NURMBERG, P. L.; LAMBERT, E. S. Avaliação de genótipos de batata (Solanum tuberosum L.) nas safras das águas e inverno no sul de Minas Gerais. Ciência e Agrotecnologia, Lavras, v. 23, n.4, p.777-784, 1999. 
MENEZES, C. B. de; PINTO, C. A. B. P.; NURMBERG, P. L.; LAMBERT, E. S. Combining ability of potato genotypes for cool and warm seasons in Brazil. Crop Breeding and Applied Biotechnology, Londrina, v. 1, n.2, p.145-157, 2001.

MENZEL, C. M. Tuberization in potato at high temperatures: interaction between temperature and irradiance. Annals of Botany, London, v. 55, p.35-39, 1985.

MOORBY, J. The production, storage and translocation of carbohydrates in developing potato plants. Annals of Botany, London, v. 34, n.2, p.297-308, 1970.

PRANGE, R. K.; McRAE, K. B.; MIDMORE, D. J.; DENG, R. Reduction in potato growth at high temperature: role of photosynthesis and dark respiration. American Potato Journal, Orono, v. 67, n.6, p.357-369, 1990.

RADFORD P.J. Growth analysis formulae - their use and abuse. Crop Science, Madison, v. 7, n.3, p.171-175, 1967.

REYNOLDS, M. P.; EWING, E. E.; OWENS, T. G. Photosynthesis at high temperature in tuber-bearing Solanum species. Plant Physiology, v. 93, p.791-797, 1990.

SILVA, L. A. S.; PINTO, C. A. B. P. Duration of the growth cycle and the yield potential of potato genotypes. Crop Breeding and Applied Biotechnology, v. 5, p.20-28, 2005.

TAIZ, L.; ZEIGER, E. Fisiologia vegetal. 4. ed. Porto Alegre: Artmed, 2009. 884p.

THOMAS H.; HOWARTH C.J. Five ways to stay green. Journal of Experimental Botany, Eynsham, v. 51, p.329-337, 2000.

VALE, F.X.R.; FERNANDES FILHO, E.I.; LIBERATO, J.R.; ZAMBOLIM, L. Quant - A software to quantify plant disease severity. In: INTERNACIONAL WORKSHOP ON PLANT DISEASE EPIDEMIOLOGY, 8., 2001, Ouro Preto. Proceedings... Ouro Preto: International Society of Plant Phatology, 2001. p. 160.

VAN DAM, J.; KOOMAN, P. L.; STRUIK, P. C. Effects of temperature and photoperiod on early growth and final number of tuber in potato (Solanum tuberosum L.). Potato Research, Wageningen, v. 39, n.1, p.51-62, 1996.

VAN DER ZAAG, D. E.; BURTON, W. G. Potential yield of the potato crop and its limitations. In: Conference Survey Papers, 7th, 1978, Warsaw. Annals... Warsaw, Poland: EAPR, 1978. p. 7-22.

WOLF, S.; MARANI, A.; RUDICH, J. Effects of temperature and photoperiod on assimilate partitioning in potato plants. Annals of Botany, London, v. 66, n.5, p.513-520, 1990. 